\title{
ANALISIS SPASIAL PERSEBARAN USAHA KECIL MENENGAH DI KABUPATEN SLEMAN DAERAH ISTIMEWA YOGYAKARTA
}

\author{
Ika Afianita Suherningtyas ${ }^{1}$ \\ 1Universitas Amikom Yogyakarta \\ Jl. Ringroad Utara Condongcatur Depok Sleman DIY \\ e-mail: ikaafianita@amikom.ac.id
}

\begin{abstract}
Abstrak
Pengembangan ekonomi kewilayahan menjadi salah satu isu dalam mendukung persaingan usaha secara global (Phijaisanit, 2017). Usaha Mikro Kecil Menengah (UMKM) sebagai salah satu roda perekonomian rakyat memiliki peran penting dalam membuka lapangan pekerjaan dan mengurangi pengangguran di Indonesia. Tujuan dari penelitian ini adalah untuk mengetahui potensi pengembangan UMKM di Kabupaten Sleman ditinjau dari kondisi kependudukan dan mengetahui persebaran UMKM di Kabupaten Sleman dan analisis potensi pengembangan UMKM di Kabupaten Sleman. Metode penelitian menggunakan pendekatan kuantitatif dengan menggunakan data sekunder tentang jumlah UMKM di Kabupaten Sleman. Hasil penelitian menunjukkan tipe piramida penduduk Kabupaten Sleman adalah tipe ekspansif dengan kondisi usia 2029 paling banyak (termasuk dalam golongan usia produktif), potensi ini dapat dikembangkan dengan melakukan kegiatan usaha untuk mengurangi pengangguran. Kondisi UMKM dengan jumlah tertinggi adalah kelas sedang dengan nilai 41\%, jumlah UMKM paling banyak masih rendah dengan nilai $24 \%$. Melalui data analisis spasial persebaran UMKM di Kabupaten Sleman dapat menjadi dasar pengambilan kebijakan dalam pengembangan UMKM oleh pemerintah maupun stakeholder.
\end{abstract}

Kata kunci: spasial, UMKM, kebijakan.

\begin{abstract}
Regional economic development is one of the issues in supporting business competition globally (Phijaisanit, 2017). Usaha Mikro Kecil Menengah (UMKM) as one of the wheels of the people's economy have an important role in opening jobs and reducing unemployment in Indonesia. The purpose of this study was to find potention in terms of population conditions and to know out the distribution of UMKM in Sleman Regency and analysis of UMKM development potential in Sleman Regency. The research method uses a quantitative approach using secondary data about the number of UMKM in Sleman Regency. The results showed that the pyramid type of the population of Sleman Regency is expansionary with the condition of the age of 20-29 at the most (included in the productive age group), this potential can be developed by conducting business activities to reduce unemployment. The highest total number is the moderate class with a value of $41 \%$, the highest. Through data on the distribution of UMKM several subdistricts in Sleman Regency have good potential with an indication of the number of UMKM and turnover has a high class, namely Sleman District, Ngaglik District, and Kalasan District. Through data spatial analysis of the distribution of UMKM in Sleman Regency can be the basis of policy making in the development of UMKM by the government and stakeholders.
\end{abstract}

Keywords: spatial, UMKM, policy 


\section{PENDAHULUAN}

Kegiatan usaha sebagai salah satu roda perekonomian masyarakat pada periode akhir ini semakin memiliki persaingan yang ketat, baik secara nasional maupun global. Hal tersebut terjadi semenjak adanya program kerjasama perdagangan antar negara seperti Asean Economic Community (AEC) (Muta'ali, 2015). Disisi lain, pemerintah telah mencanangkan Gerakan Kewirausahaan Nasional berdasarkan Intruksi Presiden Nomor 4 Tahun 1995 yang memiliki tujuan meningkatkan wirausaha di Indonesia untuk memperluas lapangan pekerjaan dan mengurangi pengangguran. Usaha Mikro Kecil Menengah (UMKM) sebagai salah satu roda perekonomian wilayah merupakan komponen penting dalam kegiatan ekonomi masyarakat di Indonesia khususnya salah satunya di Provinsi Daerah Istimewa Yogyakarta (DIY) (Hamidi, 2011).

Tren perkembangan jumlah UMKM di Provinsi DIY mengalami kenaikan semenjak Tahun 2015. Tercatat jumlah UMKM adalah 220.703 UMKM, meningkat menjadi 230.047 UMKM pada tahun 2016, dan meningkat lagi 238.619 UMKM pada tahun 2017. Persentase peningkatan jumlah UMKM di DIY sejak tahun 2015 hingga 2017 mencapai 8,12\%. Persebaran jumlah UMKM di DIY tahun 2017 berdasar 4 wilayah kabupaten di DIY menunjukkan bahwa Kabupaten Sleman memiliki jumlah UMKM paling sedikit yaitu hanya 18\% dibanding dengan kabupaten lain di DIY yaitu Bantul (26\%), Gunungkidul (22\%), dan Kulonprogo (20\%) (Dinas Koperasi UKM, 2018). Di sisi lain Kabupaten Sleman juga memiliki Tingkat Pengangguran Terbuka (TPT) tertinggi dengan nilai 4,4\%, jika dibandingkan dengan kabupaten lainnya yaitu Kulonprogo hanya 1,40\%, Bantul 2,72\%, dan Gunungkidul 2,07\% (BPS, 2018b). Pembangunan ekonomi wilayah dengan pendekatan geografi dan disajikan secara spasial kewilayahan dapat menjadi salah satu bahan dasar kajian perencanaan strategi untuk melakukan pengembangan potensi kewilayahan suatu daerah (Rilanto, 2004). Kondisi tersebut sinergi dengan salah satu pilar utama dalam integrasi AEC secara global yaitu pada pilar pembangunan ekonomi wilayah, dimana dalam hal ini pendekatan geografi memiliki peran yang penting sebagai dasar penentuan kebijakan (Thirawat, 2017).

Melalui permasalahan terkait kondisi UMKM Kabupaten Sleman diamana memiliki jumlah UMKM yang sedikit dan angka TPT masih tinggi, perlu dilakukan identifikasi analisis spasial kondisi persebaran UMKM di Kabupaten Sleman sebagai bahan dalam pengambilan kebijakan tentang pengembangan UMKM di Kabupaten. Analisis spasial persebaran UMKM menggunakan data jumlah UMKM per kecamatan dapat menjadi bahan rujukan untuk pengembangan UMKM di Kabupaten Sleman agar mampu bersaing baik dalam skala lokal, nasional, maupun global. Diharapkan dengan adanya optimalisasi potensi UMKM dapat membuka semakin banyak lapangan usaha dan mengurangi pengangguran khsusunya di Kabupaten Sleman.

\section{METODE PENELITIAN}

Metode penelitian yang digunakan adalah menggunakan metode kuantitatif dengan analisis secara deskriptif. Penelitian deskriptif dilakukan secara neturalistik, dimana objek penelitian dibiarkan apa adanya tanpa ada perlakuan khusus untuk menggambarkan masalah faktual dan aktual objek penelitian (Sudarma, 2014). Penentuan objek penelitian diambil secara keseluruhan yaitu seluruh populasi UMKM di Kabupaten Sleman. Populasi dapat digunakan dalam penelitian kuantitatif (Usman, 2014). Hal ini sesuai dengan penelitian yang dilakukan terkait persebaran UMKM di Kabupaten Sleman, 


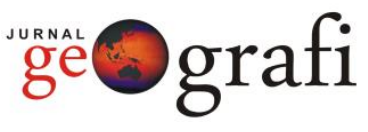

dimana peneliti tidak melakukan perlakuan khusus terhadap objek penelitian yang kemudian disajikan secara spasial. Data yang digunakan adalah data sekunder tentang UMKM dari Dinas Koperasi dan UMKM Tahun 2017. Pengolahan data dilakukan dengan klasifikasi menggunakan rumus sturgess untuk mengetahui kelas jumlah UMKM di Kabupaten Sleman. Adapun hasil klasifikasi dilakukan pengolahan data secara spasial dengan menggunakan software ArcGIS. Hasil yang diperoleh adalah pemetaan klasifikasi UMKM Kabupaten Sleman, persebaran UMKM berdasarkan bidang usaha, dan omset yang diperoleh UMKM per kecamatan di Kabupaten Sleman.

\section{HASIL DAN PEMBAHASAN \\ Letak Geografis dan Kondisi \\ Kependudukan}

Kabupaten Sleman merupakan wilayah bagian utara Provinsi DI. Yogyakarta, yang berbatasan langsung dengan Provisi Jawa Tengah. Wilayah Kabupaten Sleman terbentang mulai $110^{\circ}$ $13^{\prime} 00^{\prime \prime}$ samapai dengan $110^{\circ} 33^{\prime} 00^{\prime \prime}$ Bujur Timur dan mulai $7^{\circ} 34^{\prime} 51^{\prime \prime}$ Lintang Selatan. Ketinggian wilayah adalah antara 100-2.500 mdpl. Luas wilayah Kabupaten Sleman adalah 574,82 km², yang terdiri dari 17 kecamatan, 86 desa, dan 1.212 padukuhan. Batas wilayah meliputi sebelah utara adalah Kabupaten Boyolali, sebelah timur adalah Kabupaten Klaten, sebelah selatan adalah Kabupaten Bantul, Kota Yogyakarta, dan sebelah barat adalah Kabupaten Kulonprogo dan Kabupaten Magelang (BPS, 2018a).

Total jumlah penduduk Kabupaten Sleman Tahun 2017 adalah 1.193.512 jiwa. Secara tren grafik jumlah penduduk Kabupaten Sleman dari tahun sebelumnya yaitu tahun 2015, 2016, dan 2017 mengalami kenaikan (gambar 1). Adapun distribusi jumlah penduduk menurut kelompok umur 5 tahunan, melalui hasil dari pembuatan piramida penduduk diketahui bahwa tipe piramida penduduk Kabupaten Sleman adalah ekspansif dengan kecenderungan kelompok usia muda lebih banyak jumlahnya 20-24 dan 25-29 (gambar 2). Usia tersebut juga masuk ke dalam usia produktif dimana pada usia tersebut banyak penduduk melakukan kegiatan produktif/ bekerja untuk menghaslkan nilai ekonomi.

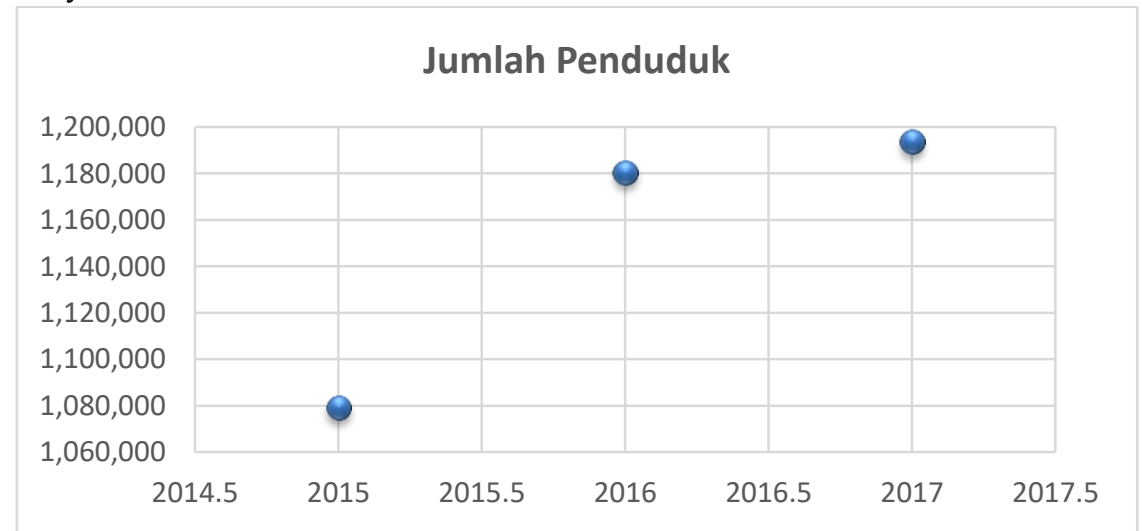

Gambar 1. Tren Jumlah Penduduk Kab. Sleman Tahun 205. 2016, dan 2017

Jika ditinjau dari potensi usia produktif di Kabupaten Sleman, maka pembukaan lapangan kerja perlu dilakukan di wilayah Kabupaten Sleman untuk meningkatkan sumberdaya manusia di wilayah tersebut. Peningkatan kualitas sumberdaya manusia, salah satunya dapat dilakukan dengan membuka kesempatan kerja seluas-luasnya bagi masyarakat. Salah satu peluang yang dapat dilakukan adalah dengan membuka usaha/ sebagi wirausaha dengan membangun UMKM di seluruh 
wilayah di Kabupaten Sleman. Melalui UMKM di wilayah yang dikembangkan secara maksimal dapat membuka lapangan pekerjaan dan mengurangi pengangguran di Kabupaten Sleman. Potensi lainnya di Kabupaten Sleman adalah adanya dukungan lokasi geografis Kabupaten
Sleman yang strategis dimana berada di jalur perbatasan Provinsi Jawa Tengah dan Provinsi DI. Yogyakarta, maka memudahkan arus mobilitas, distribusi, dan jaringan pemasaran bagi pelaku usaha UMKM.

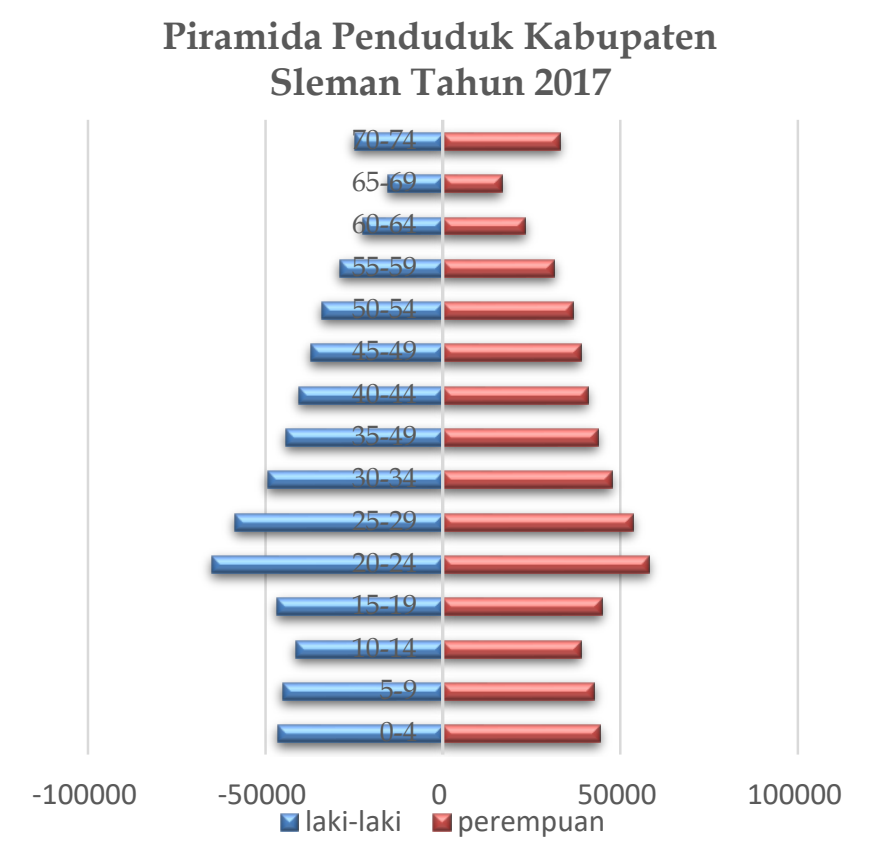

Gambar 2. Piramida Penduduk Kabupaten Sleman Tahun 2018

\section{Persebaran Klasifikasi Jumlah UMKM}

Masyarakat merupakan salah satu komponen penting dalam upaya pengembangan dan pembangunan suatu wilayah. UMKM sebagai bagian dalam kelompok masyarakat memiliki peran positif dalam pembangunan karena melalui kegiatan UMKM dapat meningkatkan kualitas sumberdaya manusia yang secara aktif, inovatif, dan produktif menghasilkan nilai ekonomi (Theresia, 2015). Maka, identifikasi persebaran jumlah UMKM penting dilakukan sebagai salah satu dasar bahan kajian dalam perencanaan pembangunan daerah, khususnya dalam hal ini adalah Kabupaten Sleman.

Jumlah UMKM Kabupaten Sleman Tahun 2017 sendiri berjumlah 31.225 UMKM yang tersebar di 17 kecamatan. Melalui perhitungan kalsifikasi dengan rumus sturgess diperoleh 3 klasifikasi jumlah UMKM di Kabupaten Sleman seperti pada tabel 1.

Tabel 1. Rentang Klasifikasi Jumlah UMKM

\begin{tabular}{c|c}
\hline klas & rentang nilai \\
\hline rendah & $783-1.525$ \\
\hline sedang & $1.526-2.268$ \\
\hline tinggi & $2.269-3.009$
\end{tabular}

Sumber: Olah data sekunder, 2018 


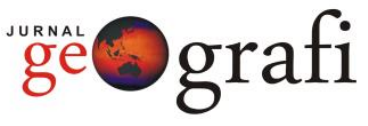

Berdasarkan hasil klasifikasi jumlah UMKM Kabupaten Sleman (gambar 3), sebagaian besar jumlah UMKM adalah sedang dengan jumlah 7 kecamatan, rendah 6 kecamatan, dan hanya 4 kecamatan yang jumlah UMKM tinggi. Total jumlah tertinggi adalah kelas sedang dengan nilai $41 \%$, jumlah UMKM paling banyak masih rendah dengan nilai $24 \%$.

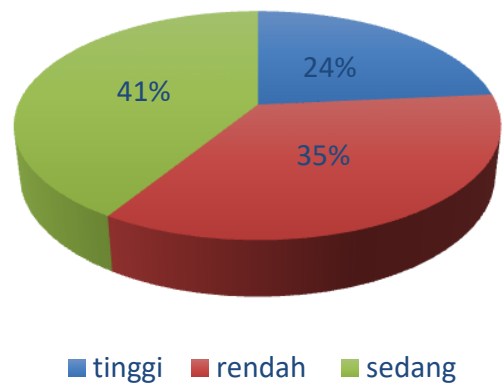

Gambar 3. Diagram Prosentase Jumlah UMKM Kabupaten Sleman.

Persebaran jumlah UMKM dengan kelas tinggi terdapat di 4 kecamatan di Kabupaten Sleman, meliputi Kecamatan Tempel, Kecamatan Ngaglik, Kecamatan Sleman, dan Kecamatan Kalasan. Empat kecamatan tersebut memiliki potensi unggul dalam mengambarkan kondisi
UKM yang ada. Hal ini ditinjau dari kondisi jumlah UMKM dengan nilai 2.269 - 3.009 UMKM. Melalui kondisi tersebut, tentu saja mampu menyerap tenaga kerja yang sebanyak 73.141 orang untuk menjalankan kegiatan UMKM.

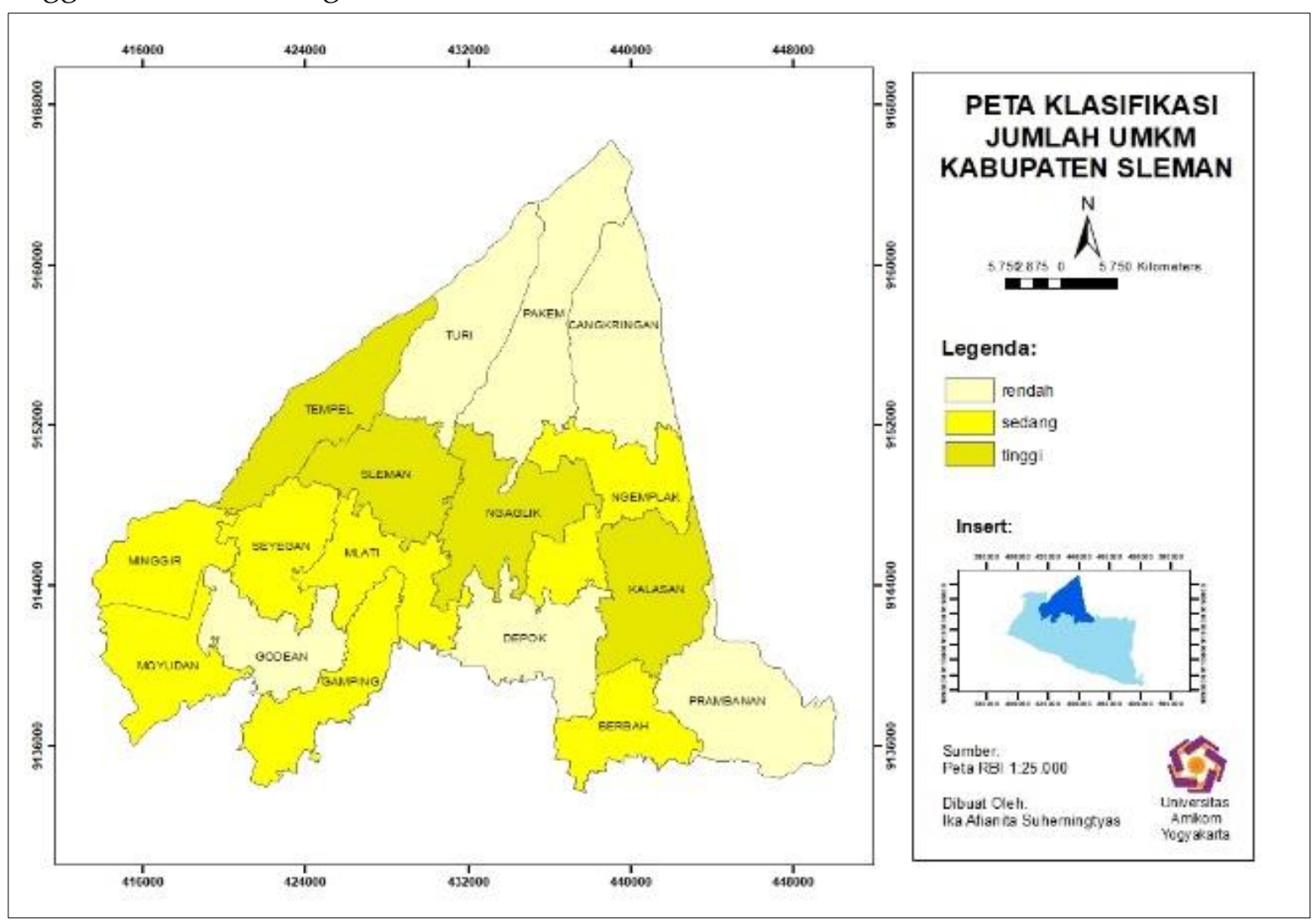

Gambar 4. Peta Klasifikasi Jumlah UMKM Kabupaten Sleman 
Skala usaha yang paling banyak dikerjakan oleh UMKM di empat kecamatan klas tinggi adalah skala usaha mikro dengan bisang usaha paling banyak pada bisnis kuliner. Kondisi ini sesuai dengan lokasi geografis keempat kecamatan yang berada pada jalur transportasi utama Provinsi DI. Yogyakarta dengan Kabupaten Magelang dan Kabupaten Klaten Provinsi Jawa Tengah.

Klas rendah dengan jumlah UMKM hany 783 - 1.525 usaha dijumpai pada 6 kecamatan di Kabupaten Sleman. Kecamatan tersebut adalah Kecamatan Turi, Kecamatan Depok, Kecamatan Cangkringan, Kecamatan Pakem, Kecamatan Prambanan, dan Kecamatan Godean, sedangkan untuk klas sedang antara lain adalah Kecamatan Minggir dan Kecamatan Moyudan. Potensi pengembangan UMKM dapat dilakukan dengan mengembangkan sektor wisata, terutama di daerah yang berada di sekitar kawasan Gunungapi Merapi yautu Turi, Pakem, dan Cangkringan. Desa wisata dan pengembangan industri kerajinan dapat menjadi pilihan untuk pengembangan UMKM agar semakin berkembang pada daerah yang UMKM masih rendah dan sedang.

Adanya kemajuan teknologi juga menjadi potensi tersendiri untuk pengembangan UMKM di Kabupaten Sleman. Melalui hasil produk dan jasa UMKM yang telah dibuat dapat di promosikan melalui internet dan fasilitas $e$ commerce yang sedang berkembang pesat pada saat ini. Dalam rangka menunjang kemajuan UMKM tersebut pemerintah perlu melakukan sosialisasi kepada masyarakat dan pelatihan tentang teknologi internet. Masyarakat sebagai pelaku UMKM yang memiliki wawasan dan pengetahuan dapat mengembangkan usahanya agar semakin maju. Apabila UMKM maju dengan indikasi omset yang meningkat dan penyerapan tenaga kerja yang banyak dapat turut serta dalam meningkatkan kualitas sumberdaya manusia. Kualitas sumberdaya manusia yang meningkat mampu mensejahterakan masyarakat sehingga kebutuhan ekonomi juga mampu terpenuhi.

Potensi UMKM Kabupaten Sleman sangat besar, jika ditinjau dari kondisi kependudukan dimana banyak usia produktif, maka dapat diberikan sosialisasi dan pelatihan untuk membuka usaha sehingga mampu membuka lapangan kerja dan mengurangi pengangguran

Jika ditinjau dari kondisi geografis, Kabupaten Sleman berada pada lokasi yang strategis karena berada pada perbatasan dengan Provinsi Jawa Tengah. Arus mobilisasi tentu saja tinggi di daerah ini, kondisi ini dapat dimanfaatkan sebagai peluang usaha membuka usaha kuliner, industri kerajinan, dan wisata.

Kondisi UMKM yang ada di Kabupaten Sleman ini dapat menjadi acuan dalam pengembangan rencana kebijakan pemerintah maupun stakeholder. Diharapkan melalui kajian ini peningkatan kapasitas UMKM dilakukan sehingga mampu membuka lapangan pekerjaan dan mengurangi pengangguran di Kabupaten Sleman.

\section{KESIMPULAN}

Kabupaten Sleman memiliki kondisi kependudukan dengan tipe ekspansif, jika ditinjau dari piramida penduduk. Kondisi ini menunjukkan tingginya usia produktif terutama usia muda 20-24 dan 25-29. Hal ini menjadi peluang untuk mengembangkan dan membuka usaha untuk membuka lapangan pekerjaan dan mengurangi 


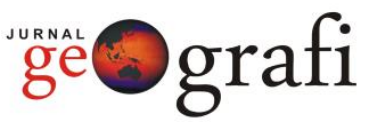

permasalahan pengangguran di Kabupaten Sleman.

Kondisi UMKM di Kabupaten Sleman paling banyak adalah dengan jumlah sedang yaitu $41 \%$, sedangkan jumlah tinggi masih rendah yaitu hanya 24\% dari total seluruh 17 kecamatan di Kabupaten Sleman. Contoh kecamatan yang memiliki kelas tinggi adalah Kecamatan Sleman. Potensi pengembangan UMKM yang ada di Kabupaten Sleman sebagai wilayah yang berada di lokasi strategis perbatasan antara Provinsi DI. Yogyakarta dan Provinsi Jawa Tengah, dengan kondisi mobilitas tinggi adalah perdagangan, kuliner, industri, dan wisata.

Kondisi UMKM yang ada di Kabupaten Sleman ini dapat menjadi acuan dalam pengembangan rencana kebijakan pemerintah maupun stakeholder. Diharapkan melalui kajian ini peningkatan kapasitas UMKM dilakukan sehingga mampu membuka lapangan pekerjaan dan mengurangi pengangguran di Kabupaten Sleman.

\section{UCAPAN TERIMA KASIH}

Penulis mengucapkan terimakasih kepada Universitas Amikom Yogyakarta yang telah memberikan bantuan dana penelitian sehingga penelitian dapat dilaksanakan. Selain itu, terima kasih kepada civitas akademik Program Studi Geografi Universitas Amikom Yogyakarta.

\section{DAFTAR PUSTAKA}

BPS. (2018a). Kabupaten Sleman dalam Angka 2018. Daearah Istimewa Yogyakarta: BPS.

BPS. (2018b). Statistik DI. Yogyakarta. Yogyakarta: BPS.

Dinas Koperasi UKM. (2018). Laporan Rakornas. Yogyakarta: Dinas Koperasi UKM DIY.
Available at http://jurnal.unimed.ac.id/2012/index.php/geo e-ISSN: 2549-7057 | p-ISSN: 2085-8167

Hamidi, E. S. (2011). Strategi Pengembangan Usaha Mikro Kecil Dan Menengah Di Provinsi Daerah Istimewa Yogyakarta. Jurnal Ekonomi Pembangunan, 12 No. 1 J, 45-55.

Muta'ali, L. (2015). Pengembangan Kawasan Strategis Ekonomi. Yogyakarta: BPFG UGM.

Phijaisanit, E. (2017). AEC and The Changing Economic Landscape: Issue, Prospects, and Potential. In Internatonalization and managing networks in the asia pasific (pp. 7-28). UK: Elsevier.

Rilanto, S. (2004). Geografi Ekonomi. Yogyakarta: Geografi UGM.

Sudarma, M. (2014). Metodologi Penelitian Geografi. Yogyakarta: Graha Ilmu.

Theresia, dkk. (2015). Pembangunan Berbasis Masyarakat. Bandung: Alfabeta.

Thirawat, N. (2017). Managing Networks in the Asia Pacific. Internationalization and Managing Networks in the Asia Pacific. UK: Elsevier. https:/ / doi.org/10.1016/ B978-0-08100813-3.00009-2

Usman, H. (2014). Metodologi Penelitian Sosial. Jakarta: Bumi Aksara. 